\title{
Intercalibration of HRDI and WINDII wind measurements
}

\author{
M. D. Burrage, W. R. Skinner, P. B. Hays \\ Space Physics Research Laboratory, University of Michigan, Ann Arbor, MI 48109, USA
}

Received: 8 October 1996 / Revised: 3 February 1997 / Accepted: 5 February 1997

\begin{abstract}
The High Resolution Doppler Imager (HRDI) and the Wind Imaging Interferometer (WINDII) instruments, which are both on the Upper Atmosphere Research Satellite, measure winds by sensing the Doppler shift in atmospheric emission features. Because the two observation sets are frequently nearly coincident in space and time, each provides a very effective validation test of the other. Discrepancies due to geophysical differences should be much smaller than for comparisons with other techniques (radars, rockets, etc.), and the very large sizes of the coincident data sets provide excellent statistics for the study. Issues that have been examined include relative systematic offsets and the wind magnitudes obtained with the two systems. A significant zero wind position difference of $\sim 6 \mathrm{~m} \mathrm{~s}^{-1}$ is identified for the zonal component, and it appears that this arises from an absolute perturbation in WINDII winds of $-4 \mathrm{~m} \mathrm{~s}^{-1}$ and in HRDI of $+2 \mathrm{~m} \mathrm{~s}^{-1}$. Altitude offsets appear to be relatively small, and do not exceed $1 \mathrm{~km}$. In addition, no evidence is found for the existence of a systematic wind speed bias between HRDI and WINDII. However, considerable day-to-day variability is found in the quality of the agreement, and RMS differences are surprisingly large, typically in the range of $20-30 \mathrm{~m} \mathrm{~s}^{-1}$.
\end{abstract}

\section{Introduction}

The High Resolution Doppler Imager (HRDI) and the Wind Imaging Interferometer (WINDII) on the Upper Atmosphere Research Satellite (UARS) have been providing global-scale direct wind measurements in the stratosphere, mesosphere, and thermosphere since November 1991. These instruments have proven to be

Correspondence to: M. D. Burrage remarkably capable and reliable (Hays et al., 1993; Grassl et al., 1995; Sheperd et al., 1993), and neither has experienced a significant degradation in nearly 5 years of operation. HRDI provides coverage in the stratosphere $(10-40 \mathrm{~km})$ and in the mesosphere and lower thermosphere (MLT) region (50-115 km), while WINDII makes measurements in the thermosphere $(90-300 \mathrm{~km})$. Both systems determine winds by measuring the Doppler shifts of naturally occurring atmospheric spectral features (Abreu et al., 1989; Sheperd et al., 1993). HRDI observes $\mathrm{O}_{2}\left({ }^{1} \Sigma\right)$ atmospheric band absorption lines in the stratosphere and emission lines in the MLT region. For WINDII the observed emissions include those from $\mathrm{OH}, \mathrm{O}_{2}$, and $\mathrm{O}\left({ }^{1} \mathrm{~S}\right)$ in the lower thermosphere, and $\mathrm{O}\left({ }^{1} \mathrm{~S}\right), \mathrm{O}\left({ }^{1} \mathrm{D}\right)$, and $\mathrm{O}^{+}\left({ }^{2} \mathrm{P}\right)$ in the middle thermosphere. Of these, only the $\mathrm{O}\left({ }^{1} \mathrm{~S}\right)$ or green-line data had been released at the time of writing, and the $90-200-\mathrm{km}$ altitude range of these measurements yields a $90-115-\mathrm{km}$ overlap with HRDI which is the focus of the present comparison study.

The HRDI MLT wind product has been thoroughly validated in a comprehensive program of comparisons with correlative measurements, including radars (MF and meteor scatter), rockets, FPIs, and WINDII, which has been ongoing since the start of the UARS mission, and the validation techniques and results are described in Burrage et al. (1993, 1996). The validation of the WINDII green-line wind observations (Gault et al., 1996) has taken a similar approach to that used for the HRDI MLT winds. In the comparisons of HRDI and WINDII observations with other techniques, it was found that medium-frequency (MF) radars can significantly underestimate the wind speeds in the mesosphere and lower thermosphere (MLT) region (Burrage et al., 1996; Gault et al., 1996; Khattatov et al., 1996). Since until the launch of UARS MF radars were the primary source of wind information, reference models also contain these biases (Fleming et al., 1996).

The problems encountered in comparing satellite remote-sensing observations with localized data sets have been discussed by Gille et al. (1984) and Burrage et al. (1996). Ground-based instruments and rocket tech- 
niques generally provide vertical profiles more or less directly above the station, yielding essentially point measurements. In contrast, limb-viewing satellite instruments such as HRDI and WINDII give profiles which are a weighted average along the line of sight, and are thus sensitive to very different spatial scales. For example, MF radars may indicate short-term variations in the wind field due to sampling of short-period gravity waves (e.g., Lloyd et al., 1990). By contrast, HRDI and WINDII have an effective horizontal resolution of a few hundred kilometres, and therefore do not readily detect such waves. Consequently, because of the different effective spatial and temporal resolutions of the UARS and correlative measurements and the high degree of short-term atmospheric variability, the two types of technique (radar and satellite) are not really sampling the same quantity.

The use of HRDI to obtain calibration information on WINDII and vice versa avoids these difficulties. These instruments have essentially the same viewing geometry, and hundreds of coincident measurement pairs are typically available on a single day. Preliminary comparisons between the two data sets have revealed discrepancies which require further investigation. Burrage et al. (1996) demonstrated a qualitative agreement, but presented results for only 2 days. McLandress et al. (1996) employed long-term (months to years) zonal averages which indicated zero wind position offsets between HRDI and WINDII of $10 \mathrm{~m} \mathrm{~s}^{-1}$ and $5 \mathrm{~m} \mathrm{~s}^{-1}$ for the zonal and meridional components, respectively. The purpose of the present study is to confirm and quantify better these offsets by using more sophisticated analysis techniques. In addition, the length (October 1992-March 1994) of the two data sets used here has facilitated a check for temporal changes in any of these differences. The earlier studies were performed only in the geographic (zonal and meridional) frame, and it was not possible to isolate the sources of the discrepancies. This investigation further employs line-of-sight components so that, for example, the two WINDII fields of view (which may have different calibration characteristics) can be distinguished. Also, while it is well known that both HRDI and WINDII typically measure larger wind speeds than MF radars, it is necessary to determine whether there is any systematic speed bias between the two satellite instruments.

\section{Measurement techniques}

The technical approaches employed by the two instruments are rather different, and the distinctions between them are summarized in Table 1. WINDII uses an imaging field-widened Michelson Interferometer (Shepherd et al., 1993), a device which is quite different from the Fabry-Pérot used by HRDI (Hays et al., 1993). While HRDI works in spectral space, WINDII operates in optical path difference space. Unlike HRDI, which directly observes the position and shape of each line, the Michelson generates a Fourier transform of the spectrum. The phase shift derived from this interferogram gives the Doppler velocity. Both techniques yield wind profiles from the inversion of a vertical-limb-scan data set. For HRDI, the inversion is accompanied by a sequential estimation technique (Ortland et al., 1995). WINDII employs a similar inversion, but does not use sequential estimation.

HRDI and WINDII provide horizontal wind vectors by observing the same atmospheric volume from two nearly orthogonal viewing directions. The motion of the spacecraft is such that there is about an 8-min time separation between the orthogonal measurement pair. In order to provide these observational components, WINDII uses two fixed viewing directions of $45^{\circ}$ and $135^{\circ}$ to the satellite trajectory, on the cold or anti-sunward side of the spacecraft. HRDI, however, employs a single fully gimbaled telescope which can point at any azimuth, but for wind measurements uses azimuths of either $45^{\circ}$ and $135^{\circ}$ (cold side) or $225^{\circ}$ and $315^{\circ}$ (warm side). In order to obtain the closest spatial and local-time coincidences with WINDII, only cold-side HRDI data are employed in the present study. The specific measurement geometries for the two methods are therefore essentially the same. Thus, while the two instruments operate on different principles, their atmospheric viewing conditions are fairly similar. Therefore, they can provide more effective validation tests of each other than are offered by other correlative measurements.

While the spatio-temporal sampling patterns of HRDI and WINDII are similar, they are not identical, and it is important to note the differences. HRDI has a single field of view with a horizontal extent of about $75 \mathrm{~km}$. The instrument performs simultaneous measurements of the required spectral region, and a vertical profile is acquired by stepping in altitude with time. Because of the spacecraft motion the inversion employs data taken at different horizontal locations, typically over a range of $\sim 200 \mathrm{~km}$ for a complete scan. In contrast, WINDII collects an entire vertical profile simultaneously. However, a sequence of either 4 or 8 phase-stepped images is required to determine the Doppler shift and hence the line-of-sight wind (Shepherd et al., 1993), during the course of which the observed region moves at the satellite velocity. Moreover, WINDII has a horizontal field of view of $150 \mathrm{~km}$, which is treated as six independent columns. Thus, the spatio-temporal sampling of the two instruments differs in significant details, while both assume a degree of horizontal homogeneity in the wind field. Consequently, the effects of short-scale $(50-500 \mathrm{~km})$ gravity waves may represent an additional source of error for both data sets, although it has previously been assumed that this is somewhat reduced by the long $(>500 \mathrm{~km})$ line-of-sight integration paths.

\section{Analysis approach}

Data were selected from the UARS day range (days since launch) 400-914 (15 October 1992-13 March 1994) for which both WINDII $\mathrm{O}\left({ }^{1} \mathrm{~S}\right)$ winds and cold-side HRDI MLT winds (from $\mathrm{O}_{2}$ ) are available. This 
Table 1. Summary of HRDI and WINDII instruments and data sets employed in present study (* Only $45^{\circ}$ and $135^{\circ}$ azimuth data are used in comparisons with WINDII.)

\begin{tabular}{lll}
\hline & HRDI & WINDII \\
\hline Interferometer type & Fabry-Pérot & Michelson \\
Viewing directions for winds & $45^{\circ}, 135^{\circ}, 225^{\circ}, 315^{\circ *}$ & $45^{\circ}, 135^{\circ}$ \\
Altitude range $(\mathrm{km})$ & $50-115$ & $90-200$ \\
Emission observed & $\mathrm{O}_{2}\left({ }^{1} \Sigma\right)$ & $\mathrm{O}\left({ }^{1} \mathrm{~S}\right)$ \\
Estimated wind error $(90-110 \mathrm{~km})$ & $5-10 \mathrm{~m} \mathrm{~s}^{-1}$ & $5-15 \mathrm{~m} \mathrm{~s}^{-1}$ \\
\hline
\end{tabular}

criterion yielded a total of 88 suitable days. For a given altitude in the $90-115-\mathrm{km}$ overlap region, coincident HRDI/WINDII measurement pairs were obtained for a maximum horizontal separation of $500 \mathrm{~km}$ and time difference of $5 \mathrm{~min}$. Observations from the entire latitude range $\left( \pm 72^{\circ}\right)$ were employed, but data for which the solar zenith angle exceeded $80^{\circ}$ were discarded in order to avoid twilight conditions where the signal is weak and wind retrievals are less reliable. The spatial separation limit was chosen as the approximate scale of the spatial resolution of both instruments, while the maximum time difference is just over half the $\sim 8 \mathrm{~min}$ required to collect both the forward and backward view for the same geographic location. Because the measurement timing for HRDI and WINDII is not synchronized, these spatial and temporal tolerances are required to obtain an adequate statistical sample of paired observations. Each day was analyzed only if it provided at least 100 coincidences, and this restriction resulted in a total of 67 acceptable days. During the night, the emission observed by HRDI is restricted to a narrow layer which peaks at $94 \pm 2 \mathrm{~km}$ (Burrage et al., 1994). A limb scan is not performed, and so the altitude of the measured winds is uncertain. Consequently, no nighttime observations are employed in the present study.

A linear fit to the HRDI and WINDII coincident wind data was performed using the FORTRAN subroutine FITEXY from Numerical Recipes (Press et al., 1992), which assumes errors in both $x$ and $y$. The slopes and intercepts (representing wind-speed ratios and systematic offsets, respectively) were determined for each of the 67 days, and these are presented later in this report. Each of the daily data sets comprised between 200 and 500 coincident HRDI/WINDII pairs. An example of the comparisons is given in Fig. 1, which shows a scatter plot for all of the coincident HRDI and WINDII measurement pairs obtained on 17 January 1993 at an altitude of $95 \mathrm{~km}$. The wind magnitudes measured by the two systems are in good agreement for both zonal and meridional directions. Nevertheless, there is significant scatter in the figure. Although the viewing conditions are very similar, the measurement timing of the two techniques is different, and therefore the respective regions of the atmosphere which are sampled are not identical. Therefore, some geophysical differences are to be expected, particularly when there are high levels of gravity-wave activity. The reduced $\chi^{2}$ merit function for the straight-line fit is given by (Press et al., 1992)

$\chi^{2}(a, b)=\frac{1}{N} \sum_{i=1}^{N} \frac{\left(y_{i}-a-b x_{i}\right)^{2}}{\sigma_{y i}^{2}+b^{2} \sigma_{x i}^{2}}$,

where $\sigma_{x i}$ and $\sigma_{y i}$ are, respectively, the $x$ (HRDI) and $y$ (WINDII) standard deviations for the $i$ th point, $N$ is the number of data points, and $a$ is the intercept and $b$ the slope of the line. If the standard deviations (or expected uncertainties) are correctly specified one expects $\chi^{2}$ to be close to unity. However, the values of $\chi^{2}$ for both wind components in Fig. 1 are close to 4 , which implies that the uncertainties given for one or both of the HRDI and WINDII data sets are underestimated. If one of the techniques provides accurate error estimates, then this result suggests that the other underestimates the uncertainties by a factor of approximately 2 .

Due to the difficulty in obtaining a reliable regression fit when there are uncertainties in both variables, a histogram approach was implemented as an additional check, as illustrated in Fig. 2. This involved sorting the HRDI and WINDII speed ratios and differences into
(WINDII/HRDI) SPEED RATIO

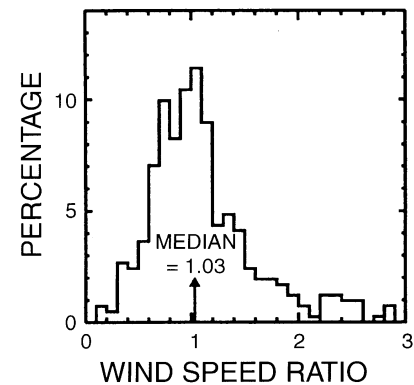

(HRDI-WINDII) WIND DIRECTION

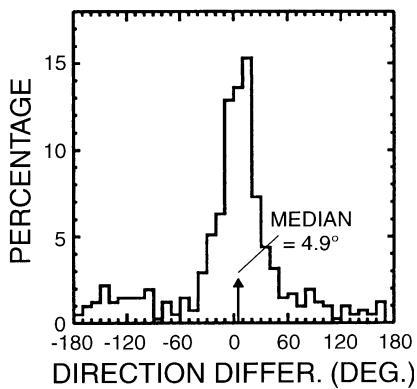

Fig. 2. WINDII/HRDI wind-speed ratios (left-hand panel) and direction differences (right-hand panel) presented as a percentage of all the available coincidences at an altitude of $95 \mathrm{~km}$ (total of 412) on 17 January 1993
Fig. 1. Scatter plot of WINDII and HRDI zonal and meridional winds for all coincident measurements at an altitude of $95 \mathrm{~km}$ (total of 412) occurring on 17 January 1993

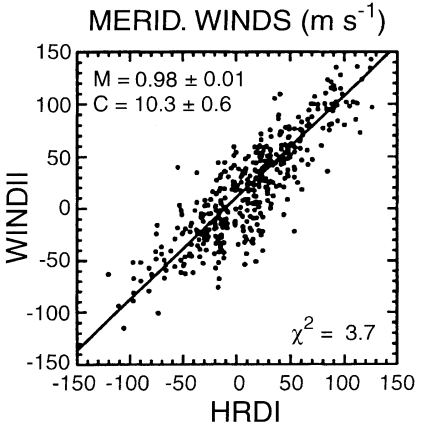

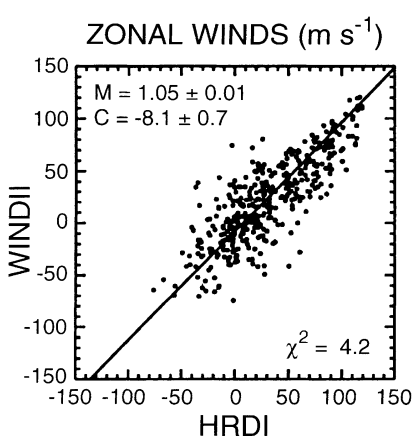


bins, and determining the median values of the resulting distributions. Wind magnitudes of less than $5 \mathrm{~m} \mathrm{~s}^{-1}$ in either data set were discarded in order to avoid the spurious ratios obtained when the numerator or denominator approaches zero. Under some circumstances, particularly for larger degrees of scatter, the histogram method is more robust than the regression fit technique, since the latter can give undue weighting to outlying points. In this case, the WINDII/HRDI speed ratio obtained (1.03) is consistent with the results from the regression method. The direction difference $\left(4.9^{\circ}\right)$ is very small.

It has recently been demonstrated (S. J. Franke, private communication, 1996) that when two measurements of the same variable which have different variances are fitted with a straight line, unless the variance difference is correctly accounted for the resulting slope is misleading. In particular, the measurement set with the larger variances will appear to be biased to larger values. The same tendency is found for the histogram method. This could partially explain some of the large biases found between HRDI and the MF radars (Burrage et al., 1996), if the HRDI uncertainties are underestimated. The problem can be avoided by employing long-term (seasonal) averages, which reduces the standard deviations of both measurement sets to relatively small values. However, seasonal comparisons made by Burrage et al. (1996) confirmed that there remains a significant $\mathrm{HRDI} /$ radar bias which is not an artifact of the analysis technique. Burrage et al. (1996) also demonstrated that while the HRDI variances were significantly larger than those of the MF radars, the HRDI and WINDII variances were statistically very similar, and so the present study was not expected to suffer from this problem. However, the reduced $\chi^{2}$ value obtained in Fig. 1 apparently contradicts the earlier finding. This issue is further discussed later in the report.

Comparisons between HRDI and WINDII typically yield only relative information rather than indicating which technique contains the error. In the case of the zero wind positions, it is believed that the HRDI determinations are highly accurate, and the next section attempts to justify this.

\section{HRDI zero wind positions}

Data from HRDI are continuously under review to ensure that they are of the best possible quality. In order to optimize the HRDI MLT wind product, the zero reference position (the position on the detector of the observed emission line in the absence of a windinduced Doppler shift) requires periodic adjustments. Changes in this parameter, which are quantified using HRDI calibration data, HRDI geophysical measurements, and correlative data (Burrage et al., 1993, 1996), can be significant. For example, on 17 April 1995 HRDI was shut down due to the UARS power shortage caused by the final failure of the solar array drive. Subsequently, the instrument became very cold, and when reactivated in July 1995 was found to have exhibited a significant change $\left(10 \mathrm{~m} \mathrm{~s}^{-1}\right)$ in the zero position. Version 11 of the HRDI data product, released in early 1996, corrects this offset.

Recently, a new technique for more accurate determination of the HRDI zero positions has been developed. This does not require correlative data, but relies on the capability of the instrument to look on both sides of the spacecraft, which is provided by a fully gimbaled telescope. WINDII, by contrast, employs two orthogonal viewing ports fixed on one side of the spacecraft. If warm-side (the sun-side of the orbit plane) and cold-side HRDI data are compared for locations which should have approximately the same geophysical winds (i.e., same spatial and local time coordinates), then the offset or error in the zero position is isolated. The geometry of the measurement approach is schematically illustrated in Fig. 3. Consider a pair of forward and backward LOS wind measurements for the same point in latitude and local-time space made on the warm side of the spacecraft. About 6 days later, the same point in latitude/ local-time space may be observed from the cold side. If it is assumed that the prevailing geophysical wind $V$, which has components $V_{x}$ and $V_{y}$ along the two LOS directions, does not change during this period, then the measurements are related to the geophysical wind components and the offset errors as follows:

$V_{W_{B}}=V_{y}+\varepsilon_{B}$

and

$V_{C_{F}}=-V_{y}+\varepsilon_{F}$.

Combining Eqs. 1 and 2 gives

$V_{W_{B}}+V_{C_{F}}=\varepsilon_{B}+\varepsilon_{F}$,

and similarly for the $x$ direction:

$V_{C_{B}}+V_{W_{F}}=\varepsilon_{B}+\varepsilon_{F}$,

where the subscripts $W$ and $C$ denote warm and cold side, respectively, and $F$ and $B$ indicate forward and backward observations. The offset errors for forward and backward viewing, $\varepsilon_{F}$ and $\varepsilon_{B}$, are distinguished because the observed emission line falls on two quite different parts of the detector due to the change in sign

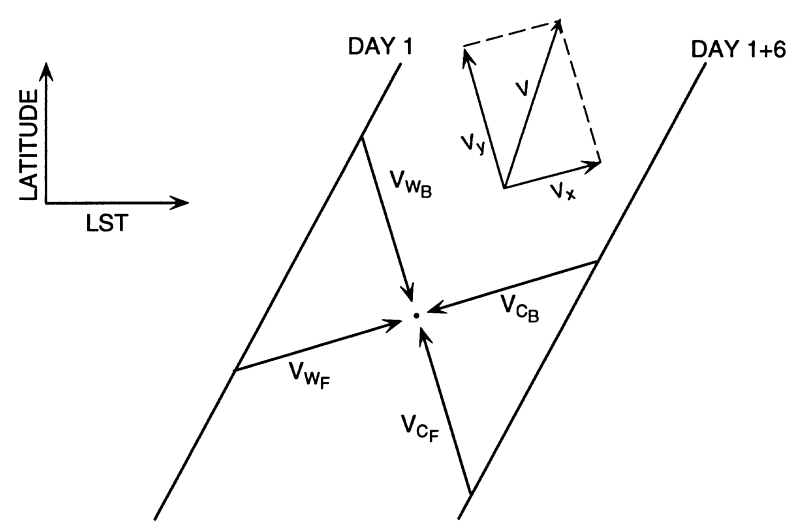

Fig. 3. Schematic illustration of the viewing geometry employed in the warm-side/cold-side zero position analysis 
of the spacecraft velocity-induced Doppler shift between the two cases.

Contributions from planetary waves are suppressed by employing zonal means. Long-term ( monthly) averaging of all available data ensures that differences arising from high-frequency geophysical components, such as gravity waves, are minimized. This analysis is conducted routinely, and will identify a change in the zero position not necessarily detected in the calibration data. Equations 4 and 5 give two independent determinations of the total offset error for version 11 of the HRDI wind data, and these are shown in Fig. 4. The two sets of results (Fig. 4a and b) are well correlated, and nearly all lie within the range $\pm 5 \mathrm{~m} \mathrm{~s}^{-1}$. Also, note that there is no obvious long-term trend or drift in the results, and the means are very similar $\left(1.4 \mathrm{~m} \mathrm{~s}^{-1}\right.$ for Fig. 4a and $0.9 \mathrm{~m} \mathrm{~s}^{-1}$ Fig. 4b). The scatter and error bars are much larger in the first part of the mission, up until about day 600 , and this is because the statistics are poorer due to the relatively few cold-side measurements made during that period. While this method indicates that the sum of the backward and forward offset errors are typically of the order of $\sim+1 \mathrm{~m} \mathrm{~s}^{-1}$, it is important to address the issue of systematic errors with an alternative and independent approach.

Acquisition and analysis of correlative data has supplemented the results of the preceding technique for identifying errors in the zero reference position. In this case, the analysis is conducted in the geographic (zonal and meridional) frame of reference. Scatter plots and regression fits of HRDI and correlative data from six different systems are presented in Fig. 5. As already explained, the slopes obtained for cases where the variances of the two techniques are quite different and not correctly specified are not reliable. This is believed to be true particularly for the Saskatoon and Christmas Island radars, where the slopes of the fitted lines almost certainly exaggerate the true wind-speed bias.

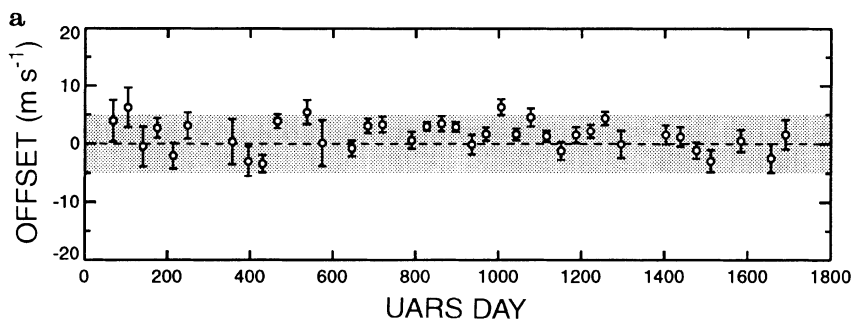

b

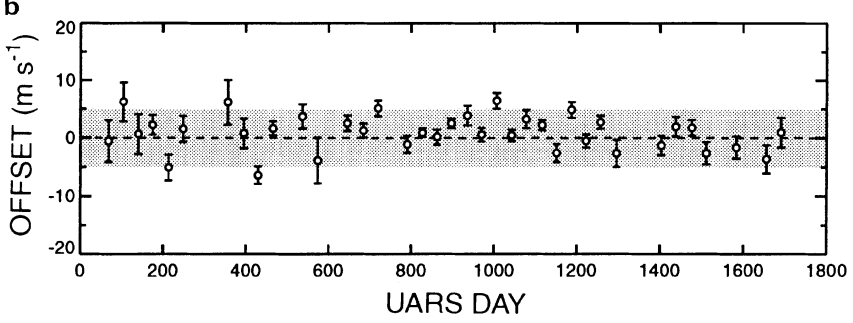

Fig. 4a, b. HRDI zero wind offset determination $\left(\varepsilon_{F}+\varepsilon_{B}\right)$ over the mission lifetime a using Eq. 4, and b using Eq. 5. The time-axis is given as UARS day number (days since the launch of the spacecraft on 12 September 1991). The $\pm 5-\mathrm{m} \mathrm{s}^{-1}$ region is shaded gray
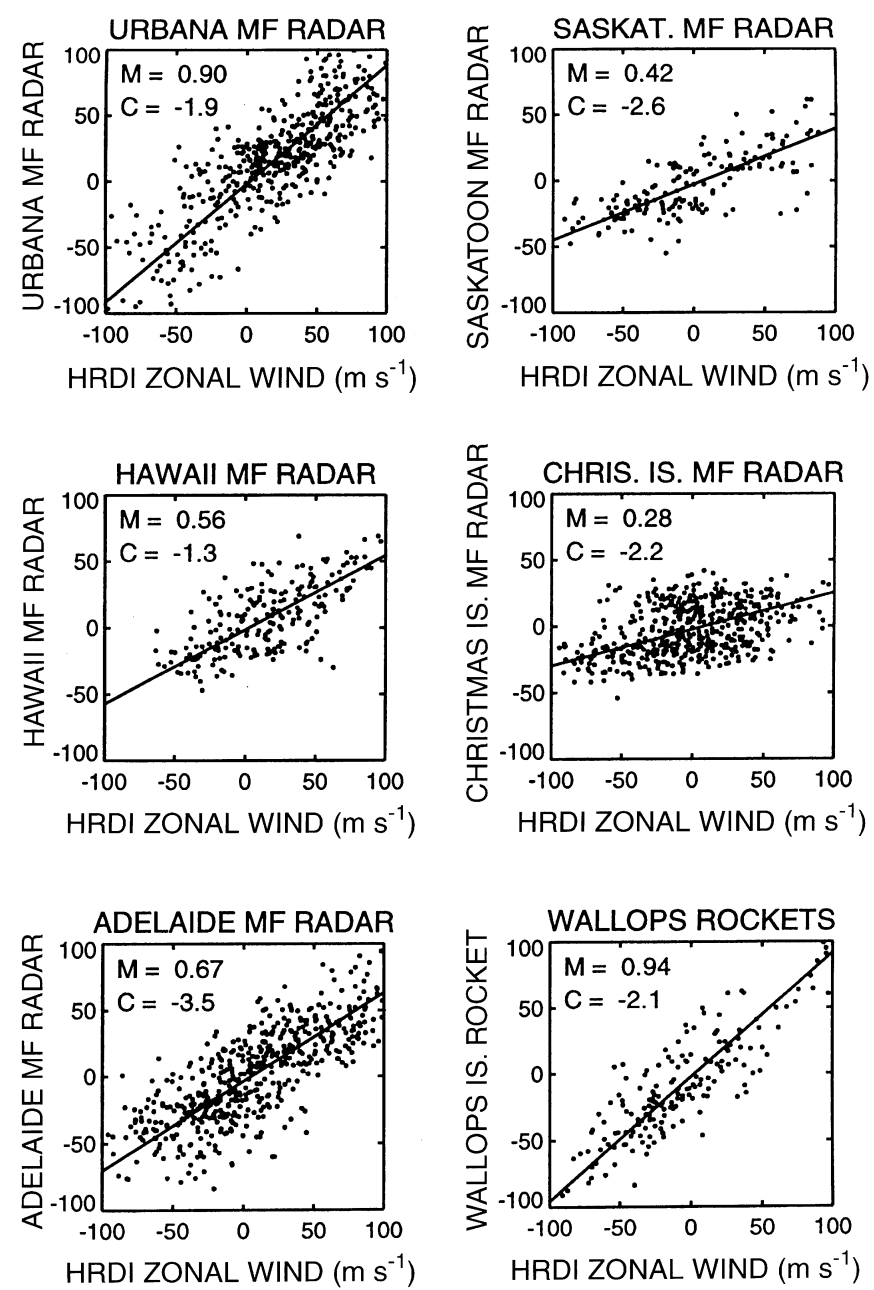

Fig. 5. Scatter plots of HRDI zonal winds in the altitude range 70-90 km against data obtained from coincidences with five different MF radars (Urbana, Saskatoon, Hawaii, Christmas Island, and Adelaide) and with rockets launched from Wallops Island during the period 1991-1995

Comparisons with HRDI of seasonal means (Burrage et al., 1996) have indicated larger speed ratios than shown in Fig. 5 (e.g., a ratio of $\sim 0.5$ for HRDI/ Christmas Island radar compared with 0.28 found here). However, notice that the intercepts are remarkably consistent, varying between -1.3 and $-3.5 \mathrm{~m} \mathrm{~s}^{-1}$. These results suggest that HRDI might have a systematic zonal wind offset of $\sim 2 \mathrm{~m} \mathrm{~s}^{-1}$, a small value which is consistent with the results of the warm- and cold-side method.

\section{HRDI/WINDII comparisons}

Figure 6 presents the slopes obtained from the regression analysis for each of the available days, for both the zonal and the meridional wind components at an altitude of $95 \mathrm{~km}$. Since the agreement between HRDI and WINDII is not expected to exhibit a seasonal variation, the time-axis is given simply as days since the launch of the spacecraft on 12 September 1991 (UARS day). The slopes represent the WINDII/HRDI wind 


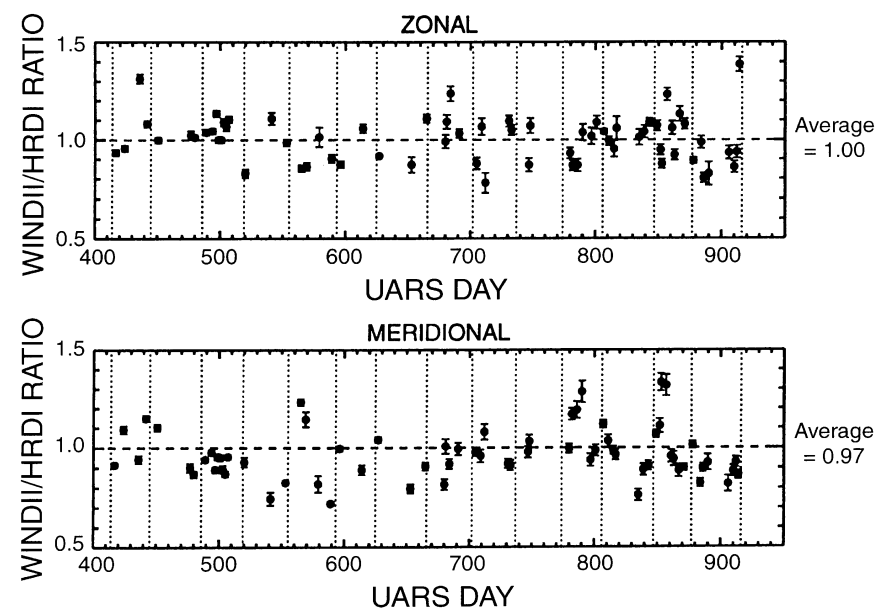

Fig. 6. Slopes obtained from the regression analysis as a function of UARS day number, for both the zonal (upper panel) and the meridional wind component (lower panel) at an altitude of $95 \mathrm{~km}$. The vertical dotted lines indicate yaw maneuver days

ratios. While there is significant scatter from day to day, the mean ratios are very close to unity ( 1.00 and 0.97 for the zonal and meridional components, respectively), although the error bars derived from the regression analysis appear anomalously small. This again suggests that the measurement uncertainties of HRDI or WINDII or both have been underestimated. the WINDII/HRDI speed ratios obtained via the histogram method are shown in Fig. 7, and the time mean value of 1.02 indicates that there is no systematic wind-speed bias between the two systems. Figure 7 also demonstrates that direction differences are typically small, with most lying within the range $\pm 10^{\circ}$. Figure 8 shows that the time-average WINDII/HRDI wind-speed ratio as a function of altitude is in the range 0.95-1.05. The altitude structure seen in the figure is probably not significant, considering the degree of scatter from day to day (see Fig. 7a); indeed the $1 \sigma$ uncertainty level for the ratio at each altitude is $\sim \pm 0.1$. Figure 8 also indicates
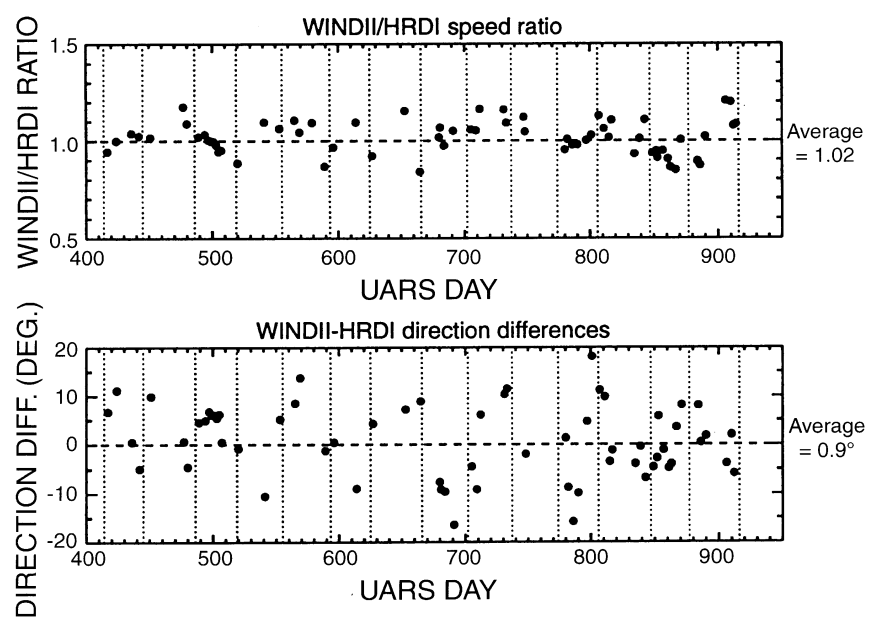

Fig. 7. WINDII/HRDI wind-speed ratios (upper panel) and direction differences (lower panel) for an altitude of $95 \mathrm{~km}$ obtained with the histogram method
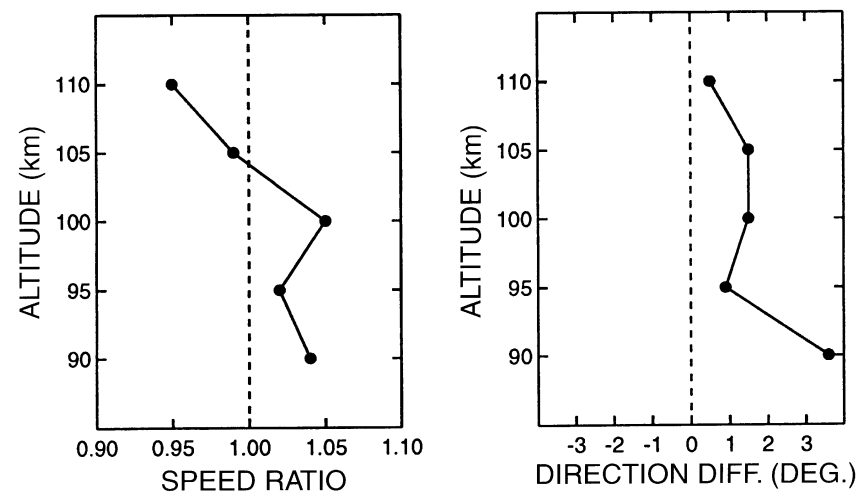

Fig. 8. Mean WINDII/HRDI wind-speed ratios (left-hand panel) and direction differences (right-hand panel) as a function of altitude obtained with the histogram method

that the direction difference is less than $4^{\circ}$ throughout the overlap region.

Figure 9 presents the intercepts provided by the regression fits, which are indicative of systematic wind offsets. Again, considerable day-to-day variation is apparent, but there is no clear long-term trend. However, there is a suggestion of systematic changes occurring after the yaw maneuvers. Yaw maneuvers, which occur approximately every 36 days, involve a $180^{\circ}$ rotation in azimuth of the UARS spacecraft, and the two states are termed forward flight and backward flight. A significant mean offset of $-6.2 \mathrm{~m} \mathrm{~s}^{-1}$ between WINDII and HRDI is found for the zonal component. By comparison, the offset for the meridional component is very small $\left(-0.7 \mathrm{~m} \mathrm{~s}^{-1}\right)$. Mean offsets for five altitudes in the range $90-110 \mathrm{~km}$ are shown in Fig. 10. This demonstrates that a systematic negative offset of about $-6 \mathrm{~m} \mathrm{~s}^{-1}$ (WINDII less than HRDI) in the zonal component exists over the entire altitude range, except at the highest altitude of $110 \mathrm{~km}$ where the offset is increased to $-10 \mathrm{~m} \mathrm{~s}^{-1}$. This result is consistent with that found in the study by McLandress et al. (1996), who obtained an offset value of $-6 \mathrm{~m} \mathrm{~s}^{-1}$ near $100 \mathrm{~km}$,
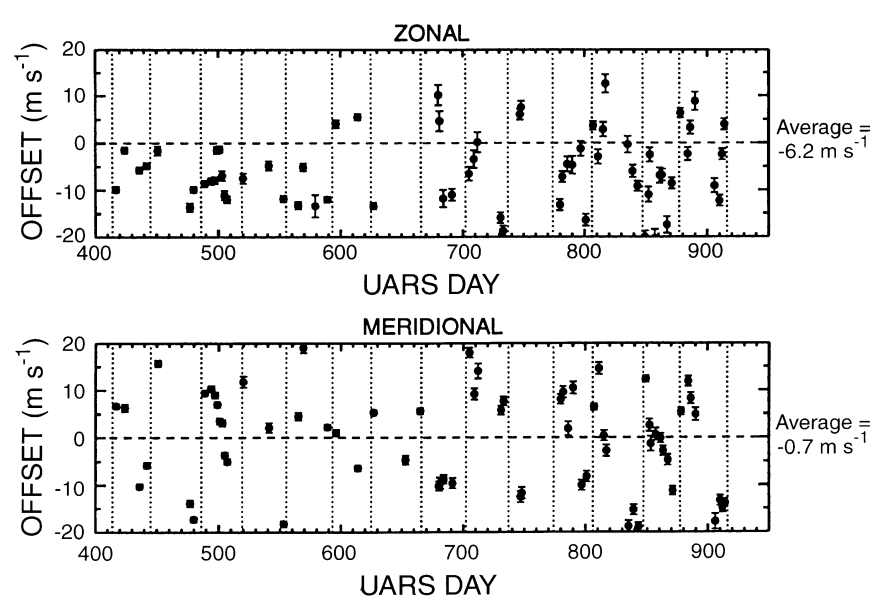

Fig. 9. Same as Fig. 6, but for the intercepts obtained from the regression analysis 

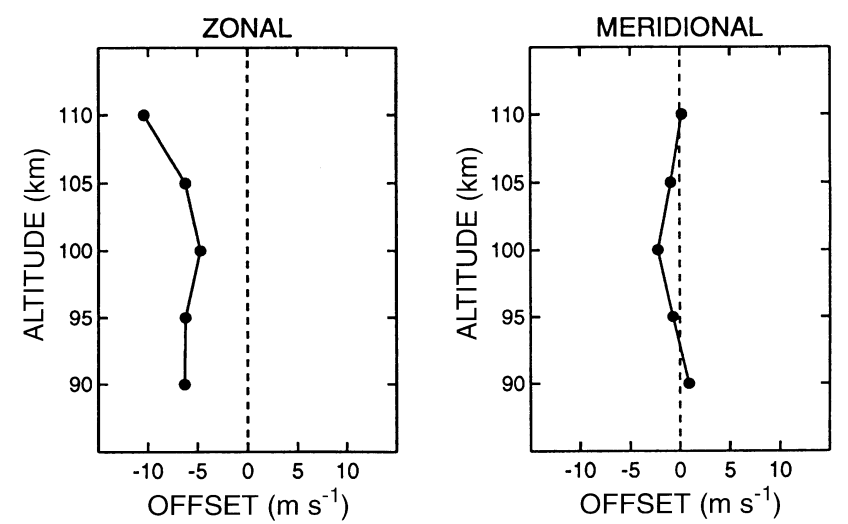

Fig. 10. Mean WINDII-HRDI offsets as a function of altitude for the zonal (left-hand panel) and meridional wind component (righthand panel)

increasing to $-10 \mathrm{~m} \mathrm{~s}^{-1}$ at $90 \mathrm{~km}$ and $-13 \mathrm{~m} \mathrm{~s}^{-1}$ at $110 \mathrm{~km}$ (see their Fig. 4). The comparison of HRDI with radars and rockets (Fig. 5) indicated that HRDI exhibits a very small zonal wind offset of $\sim \pm 2 \mathrm{~m} \mathrm{~s}^{-1}$, suggesting that the absolute zonal wind offset in WINDII is $-4 \mathrm{~m} \mathrm{~s}^{-1}$. In Fig. 10, the meridional component shows little evidence of a significant offset, which does not agree with the value of $+5 \mathrm{~m} \mathrm{~s}^{-1}$ (WINDII larger than HRDI) found by McLandress et al. (1996).

In order to obtain more information on the source of the WINDII/HRDI zonal wind offset, it is necessary to transform the comparison into the instrument LOS directions. In Fig. 11, data for each yaw cycle were averaged together, and the points are distinguished between those that used WINDII field of view 1 (FOV-1) and field of view 2 (FOV-2). FOV-1 (FOV-2) is orientated in the $45^{\circ}$ azimuth in forward (backward) flight, and the $135^{\circ}$ azimuth in backward (forward) flight. The results for the $135^{\circ}$ azimuth show a clear
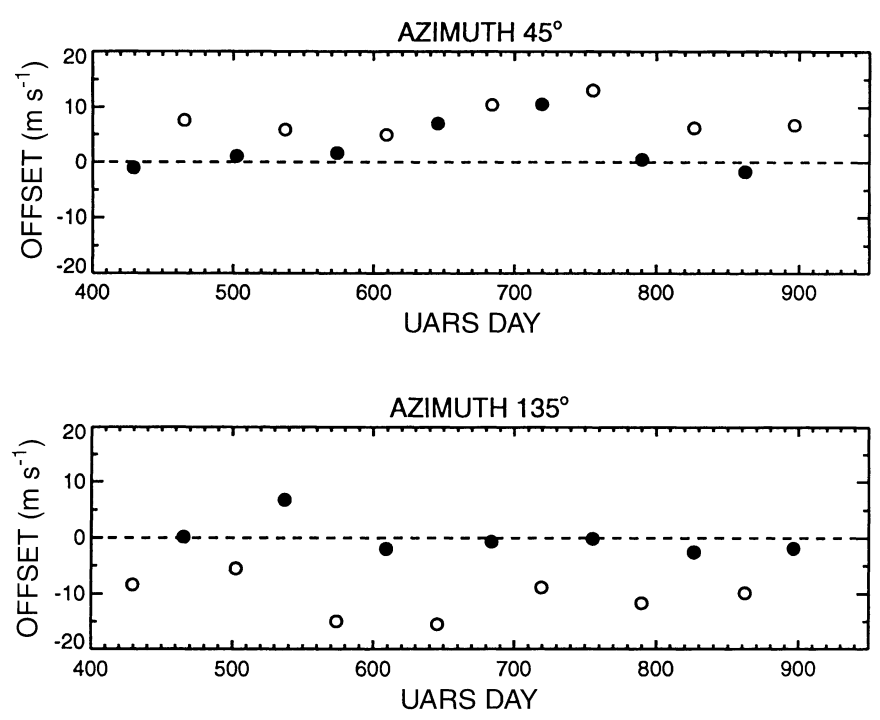

Fig. 11. WINDII-HRDI offsets for an altitude of $95 \mathrm{~km}$ in the $45^{\circ}$ azimuth (upper panel) and $135^{\circ}$ azimuth (lower panel) instrument LOS directions, averaged over each yaw cycle. Solid points denote WINDII FOV-1 and open points indicate FOV-2 pattern. While the FOV-1 offsets are all close to zero and have an average value of $0.0 \mathrm{~m} \mathrm{~s}^{-1}$, those for FOV-2 are in the range -5 to $-15 \mathrm{~m} \mathrm{~s}^{-1}$, with a mean of -10.7 $\mathrm{m} \mathrm{s}^{-1}$. The pattern for the $45^{\circ}$ azimuth is more complicated, although the FOV-2 points again exhibit a significant departure from zero $\left(+5\right.$ to $\left.+8 \mathrm{~m} \mathrm{~s}^{-1}\right)$, while the FOV-1 data do not, except for the middle of the period (days 600 to $\sim 750$ ) where a gradual drift in the positive direction is apparent in both field of views. The cause of this drift is uncertain, but it is interesting that it appears only in one azimuth. The HRDI zero wind positions are different for different azimuths, while the WINDII zero wind positions are different for FOV-1 and FOV-2, and each azimuth contains an equal mix of FOV-1 and FOV-2 data. The HRDI $45^{\circ}$ azimuth data could contain a zero drift not present in the $135^{\circ}$ azimuth which would explain this result. The overall means for the $45^{\circ}$ azimuth are $+2.6 \mathrm{~m} \mathrm{~s}^{-1}$ for FOV-1 and $+7.8 \mathrm{~m} \mathrm{~s}^{-1}$ for FOV-2. Apart from the day $600-750$ drift interval, these results, taken together with those for the $135^{\circ}$ azimuth, are consistent with there being a significant error $\left(\sim 9 \mathrm{~m} \mathrm{~s}^{-1}\right)$ in the zero wind position for the WINDII FOV-2. This error would have to change sign between forward (negative error) and backward flight (positive error). The fact that the perturbations for the two azimuths (Fig. 11) are not equal and opposite might be explained by the additional presence of a small systematic zero error $\left(1-2 \mathrm{~m} \mathrm{~s}^{-1}\right)$ in the HRDI $45^{\circ}$ azimuth data. The existence of a HRDI offset of this magnitude is possible considering the results in Figs. 4 and 5.

A simple means of determining whether relative altitude offsets exist between HRDI and WINDII is now described. The method involves repeating the comparisons several times, each time sliding the altitude grid of one of the data sets by increments of $1 \mathrm{~km}$. The actual altitude resolution of the measurements is $2.5 \mathrm{~km}$ for both instruments, and the finer $(1 \mathrm{~km})$ grid was obtained using linear interpolation. The value of the root mean square (RMS) difference is examined as a function of the relative offset between the two coincident data sets obtained on a single day. If there is no relative altitude error, then the minimum in this parameter will occur at an offset of zero. An example of the procedure for one day of coincident measurements, obtained on 24 January 1993 when UARS was in forward flight, is given in Fig. 12a. The results for the $45^{\circ}$ azimuth show a minimum at $-1 \mathrm{~km}$, suggesting that either WINDII indicates altitudes which are $1 \mathrm{~km}$ too high or HRDI registers $1 \mathrm{~km}$ too low. For the $135^{\circ}$ azimuth, there is no apparent offset. A very similar result was obtained for 3 January 1993 (Fig. 12b), when UARS was instead in backward flight. However, this behavior is not systematic. Other days have been found for which an offset of $+1 \mathrm{~km}$ appears in the $135^{\circ}$ azimuth but not in the $45^{\circ}$ azimuth, for example on 29 April 1993 (Fig. 12c) when UARS was in backward flight). As yet no pattern, such as a yaw cycle dependence, has been discerned, and the altitude issue is clearly more complex than suggested by McLandress et al. (1996), who indicated a systematic $1-\mathrm{km}$ offset, with WINDII lower than HRDI. However, 

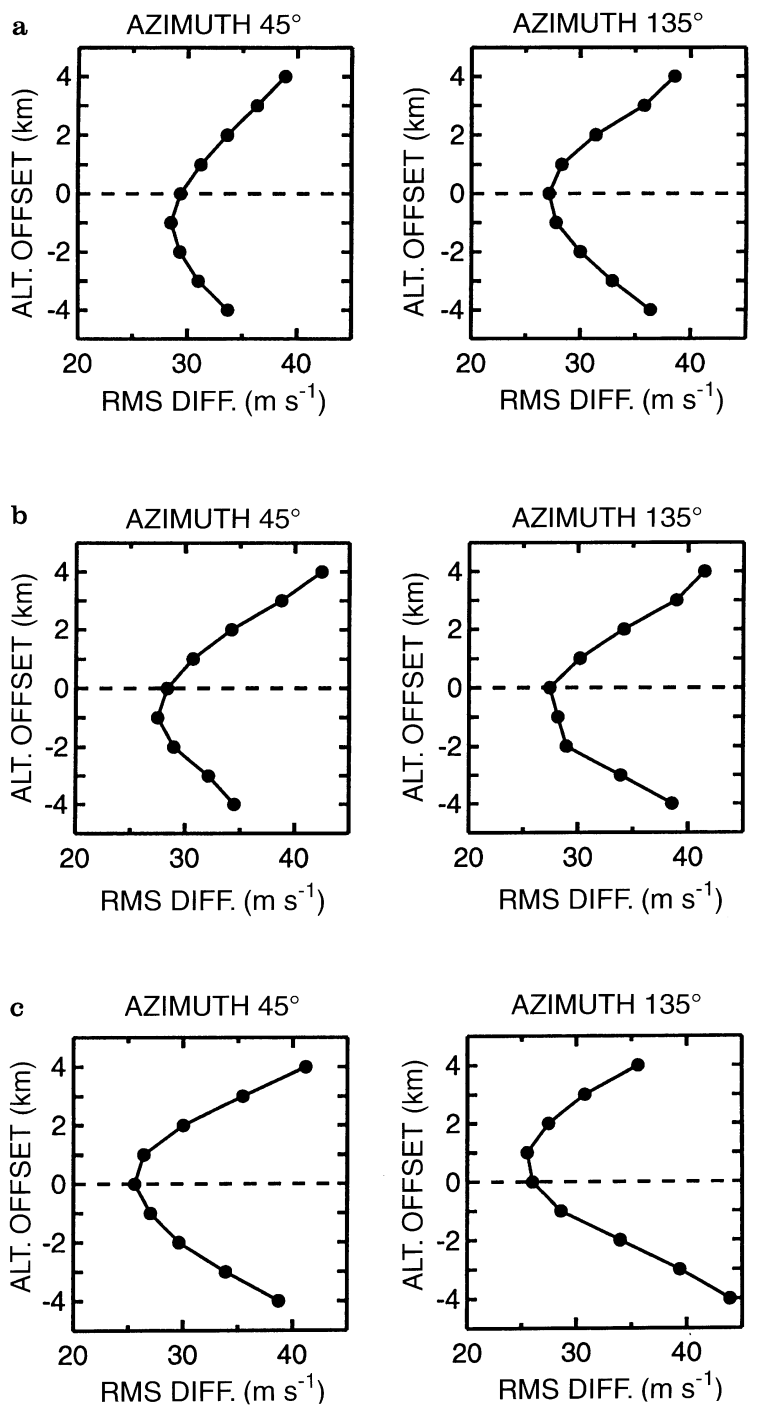

Fig. 12a-c. RMS differences as a function of the altitude offset of the WINDII data set relative to HRDI, for the $45^{\circ}$ azimuth (left-hand panels) and the $135^{\circ}$ azimuth (right-hand panels) a on 24 January 1993, b on 3 January 1993, and c on 29 April 1993

it must be remembered that this is a very small altitude uncertainty, which is within the original $1.5-\mathrm{km}$ mission specification.

Figure 13 presents the RMS differences between the HRDI/WINDII coincident data sets for all of the available days, for both the zonal and meridional wind components. The RMS values for the two components are generally quite similar, and both vary in the range of about $20-30 \mathrm{~m} \mathrm{~s}^{-1}$. These values are surprisingly large, particularly considering the typical errors quoted for both instruments (see Table 1), which are only about half the size. The fact that the reduced $\chi^{2}$ values obtained from the regression analysis for the 1-day example shown in Fig. 1 were $\sim 4$ instead of unity also suggested that the errors are underestimated. The reduced $\chi^{2}$ values for all of the available days are presented in Fig. 14. While the typical value is closer to 3 , this is still much larger than expected.
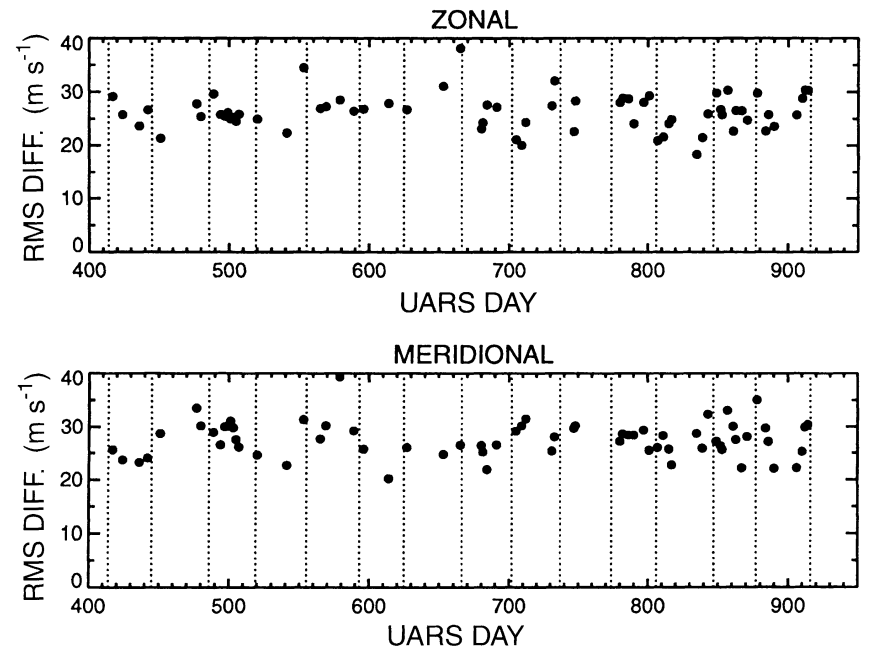

Fig. 13. RMS differences between the HRDI and WINDII wind data sets at an altitude of $95 \mathrm{~km}$, as a function of time, for the zonal component (upper panel) and meridional component (lower panel)
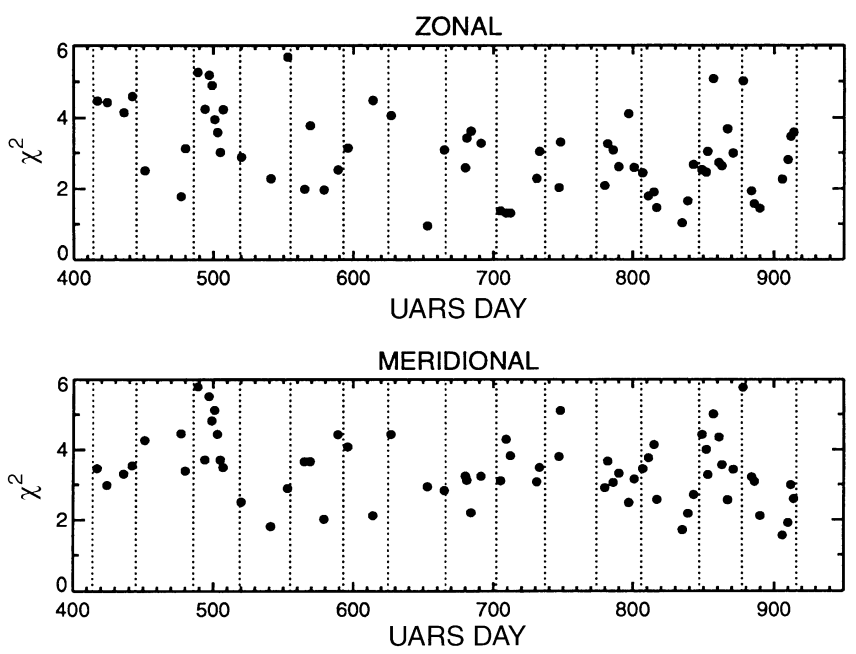

Fig. 14. Regression-fit reduced $\chi^{2}$ values obtained from the regression analysis at an altitude of $95 \mathrm{~km}$, as a function of time, for the zonal component (upper panel) and meridional component (lower panel)

Possible causes of the anomalously large $\chi^{2}$ values and RMS wind differences are now considered. The effect of the spatial separation between the HRDI and WINDII measurements was explored by reducing the separation limit from 500 to $100 \mathrm{~km}$, and then repeating the analysis. However, this did not result in a significant reduction in either $\chi^{2}$ or the RMS differences. It must be remembered that the HRDI/WINDII coincidences are not simultaneous, but fall within the range $0-5 \mathrm{~min}$. Also, one must consider the $\sim 8$-min time difference just between the forward and backward measurements of each system, which are combined to form the twodimensional vector. It is possible that the RMS differences found here might represent the background geophysical variability on such time-scales. If this is so, then the quoted measurement uncertainties should reflect this. As discussed earlier the spatial sampling 
schemes of the two instruments may give rise to additional measurement variance in the presence of short $(\sim 50-500 \mathrm{~km})$ wavelength gravity waves. The fact that HRDI and WINDII employ different emissions may also be a factor in the discrepancies. The true wind profile must be retrieved by inverting the limb-scan measurements, which are integrals of contributions from the tangent altitudes and all altitudes above them. These integrals are described by altitude weighting functions which are different for different emissions. Therefore, with the presently available data (HRDI $\mathrm{O}_{2}\left({ }^{1} \Sigma\right)$ and WINDII green line), it only makes sense to compare inverted measurements, although this provides no information on the relative effectiveness of the two inversion methods. More progress can be made in these studies when WINDII observations of the $\mathrm{O}_{2}\left({ }^{1} \Sigma\right)$ emission (the same as is observed by HRDI) become available. If there is much better agreement in uninverted measurements, then clearly the inversion techniques will require further scrutiny.

\section{Summary}

A detailed comparative analysis has been performed on HRDI and WINDII MLT wind data. The main findings of the study may be summarized as follows:

1. There is no significant wind-speed bias between HRDI and WINDII. The directions are also in good agreement.

2. WINDII appears to have an offset in the zonal wind of about $-6 \mathrm{~m} \mathrm{~s}^{-1}$ relative to HRDI, which in turn has an offset of $+2 \mathrm{~m} \mathrm{~s}^{-1}$ relative to MF radars and rockets, suggesting an absolute zonal wind bias for WINDII of $-4 \mathrm{~m} \mathrm{~s}^{-1}$. This may arise from a systematic bias in WINDII-FOV-2 (azimuth $135^{\circ}$ flying forward). No significant offset is found for the meridional component.

3. Altitude offsets exist between HRDI and WINDII, but probably do not exceed $1 \mathrm{~km}$.

4. The RMS differences between HRDI and WINDII data are typically $20-30 \mathrm{~m} \mathrm{~s}^{-1}$, which is unexpectedly large. A possible explanation is the fact that HRDI and WINDII employ different inversion methods.

5. Further progress will require comparisons at the uninverted line of sight level, which depends on the availability of WINDII $\mathrm{O}_{2}$ wind data. These will facilitate the testing of the HRDI and WINDII inversions.

Acknowledgements. This work is sponsored by NASA through contract NAS5-27751 and grant NAG5-3180. The authors gratefully acknowledge the assistance of B. H. Solheim and other members of the WINDII team in using WINDII data.

Topical Editor F. Vial thanks G. G. Shepherd and M. A. Geller for their help in evaluating this paper.

\section{References}

Abreu, V. J., A. Bucholtz, P. B. Hays, D. Ortland, W. R. Skinner, and J. H. Yee, Absorption and emission line shapes in the $\mathrm{O}_{2}$ atmospheric bands: theoretical model and limb viewing simulations, Appl. Opt., 28, 2128-2137, 1989.

Burrage, M. D., W. R. Skinner, A. R. Marshall, P. B. Hays, R. S. Lieberman, S.J. Franke, D.A. Gell, D.A. Ortland, Y.T. Morton, F. J. Schmidlin, R. A. Vincent, and D. L. Wu, Comparison of HRDI wind measurements with radar and rocket observations, Geophys. Res., Lett., 20, 1259-1262, 1993.

Burrage, M. D., N. Arvin, W. R. Skinner, and P. B. Hays, Observations of the $\mathrm{O}_{2}$ atmospheric band nightglow by the High-Resolution Doppler Imager, J. Geophys. Res., 99, 1501715023, 1994

Burrage, M. D., D. A. Gell, P. B. Hays, A. R. Marshall, D. A. Ortland, W. R. Skinner, S. J. Franke, D. C. Fritts, P. Hoffman, A. H. Manson, C. McLandress, R. Niciejewski, F. J. Schmidlin, G. G. Shepherd, W. Singer, T. Tsuda, and R. A. Vincent, Validation of mesosphere and lower thermosphere winds from the High-Resolution Doppler Imager of UARS, J. Geophys. Res., 101, 10365-10392, 1996.

Fleming, E. L., S. Chandra, M. D. Burrage, W. R. Skinner, P. B. Hays, B. H. Solheim, and G. G. Shepherd, Climatological mean wind observations from the UARS high resolution Doppler imager and wind imaging interferometer: comparison with current reference models, J. Geophys. Res., 101, 10455-10473, 1996.

Gault, W. A., G. Thuillier, G. G. Shepherd, S. P. Zhang, R. H. Wiens, W. E. Ward, C. Tai, B. H. Soheim, Y. J. Rochon, C. McLandress, C. Lathuillere, V. Fauliot, M. Hersé, C. Hersom, R. Gattinger, L. Bourg, M. D. Burrage, S. J. Franke, G. Hernandez, A. Manson, R. Niciejewski, and R. A. Vincent, Validation of $\mathrm{O}\left({ }^{1} \mathrm{~S}\right)$ wind measurements by WINDII: the WIND Imaging Interferometer on UARS, J. Geophys. Res., 101, 10405-10430, 1996.

Gille, J. C., J. M. Russell III, P. L. Bailey, L. L. Gordley, E. E. Remsberg, J. H. Lienesch, W. G. Planet, F. B. House, L. V. Lyjak, and S. A. Beck, Validation of temperature retrievals obtained by the Limb Infrared Monitor of the Stratosphere (LIMS) Experiment on NIMBUS 7, J. Geophys. Res., 89, 51475160, 1984.

Grassl, H. J., W. R. Skinner, P. B. Hays, D. A. Gell, M. D. Burrage, and D.A. Ortland, Atmospheric wind measurements with the High-Resolution Doppler Imager, J. Spacecr. Rockets, 32, 169-176, 1995.

Hays, P. B., V. J. Abreu, M. E. Dobbs, D. A. Gell, H. J. Grassl, and W.R. Skinner, The High-Resolution Doppler Imager on the Upper-Atmosphere Research Satellite, J. Geophys. Res., 98, 10713-10723, 1993.

Khattatov, B. V., M. Geller, V. Yudin, P. Hays, W. Skinner, M. Burrage, S. Franke, D. Fritts, J. Isler, A. Manson, C. Meek, R. McMurray, W. Singer, P. Hoffmann, and R. Vincent, Dynamics of the mesosphere and lower thermosphere as seen by MF radars and by the High-Resolution Doppler Imager/UARS, $J$. Geophys. Res., 101, 10393-10404, 1996.

Lloyd, N., A. H. Manson, D. J. McEwen, and C. E. Meek, A comparison of middle-atmospheric dynamics at Saskatoon $\left(52^{\circ} \mathrm{N}, 107^{\circ} \mathrm{W}\right)$ as measured by a medium-frequency radar and a Fabry-Perot interferometer, J. Geophys. Res., 95, 7653-7660, 1990.

McLandress, C., G. G. Shepherd, B. H. Solheim, M. D. Burrage, P. B. Hays, and W. R. Skinner, Combined mesosphere/thermosphere winds using WINDII and HRDI data from the UpperAtmosphere Research Satellite, J. Geophys. Res., 101, 1044110453, 1996.

Ortland, D. A., P. B. Hays, W. R. Skinner, M. D. Burrage, A. R. Marshall, and D. A. Gell, A sequential estimation techniques for recovering atmospheric data from orbiting satellites, in The upper mesosphere and lower thermosphere, Geophysical Monograph Series, Vol. 87, Ed. R.M. Johnson and T.L. Killeen, AGU, Washington, DC, pp. 329-337, 1995.

Press, W. H, S. A. Teukolsky, W. T. Vetterling, and B. P. Flannery, Numerical recipes in fortran, 2nd Edn. Cambridge University Press, New York, 1992. 
Shepherd, G. G, G. Thuillier, W. A. Gault, B. H. Solheim, C. Hersom, J. M. Alunni, J. F. Brun, S. Brune, P. Charlot, L. L. Cogger, D. -L. Desaulniers, W. F. J. Evans, R. L. Gattinger, F. Girod, D. Harvie, R. H. Hum, D. J. W. Kendall, E. J. Llewellyn,
R. P. Lowe, J. Ohrt, F. Pasternak, O. Peillet, I. Powell, Y. Rochon, W. E. Ward, R. H. Wiens, and J. Wimperis, WINDII, the Wind Imaging Interferometer on the Upper-Atmosphere Research Satellite, J. Geophys. Res., 98, 10725-10750, 1993. 